\title{
The nasal index in brazilian human skeletons
}

\author{
Larissa Chaves Cardoso Fernandes'; Marcus Vitor \\ Diniz de Carvalho; Eduardo Daruge Júnior'; Luiz \\ Francesquini Júnior ${ }^{1}$; Patrícia Moreira Rabello3; \\ Evelyne Pessoa Soriano ${ }^{2 *}$.
}

1 University of Campinas UNICAMP, Piracicaba Dental School, Department of Social Dentistry, Area of Forensic Dentistry, Piracicaba, SP, Brazil.

${ }^{2}$ University of Pernambuco - UPE Pernambuco Dental School, Master's in Forensic Sciences, Area of Forensic Dentistry, Camaragibe, PE, Brazil.

${ }^{3}$ Federal University of Paraiba UFPB, Department and Clinics and Social Dentistry, Area of Forensic Dentistry, João Pessoa, PB, Brazil.

Corresponding author: Evelyne Pessoa Soriano E-mail: evelyne.soriano@upe.br Phone number: +5581 3266-5926. Address: Estrada de Aldeia, Km 13, Cond. Torquato Castro 01 Casa 200, Camaragibe, PE, Brazil. ZIP Code: $54783-010$.

Received: March 05, 2018

Accepted: November 09, 2018

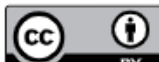

Aim: To investigate the percentage of correctness (PC) of the Nasal Index $(\mathrm{NI})$ in human skeletons for determination of sex, ancestry and estimation of age in the Brazilian population. Methods: This was a cross-sectional study of 173 human skulls belonging to the Piracicaba Dental School. 93 skeletons were males and 80 females; 34 were aged up to 39 years, 56 between 40 and 59 years, and 8360 years or older; 96 were from white individuals, 49 were from mixed-race and 28 from black individuals. High-precision digital caliper was used to measure nasal height ( $\mathrm{NH}=$ ANS-nasion) and the maximum nasal width (NW) values, which were applied into the formula $\mathrm{NI}=\mathrm{NW} / \mathrm{NH} \times 100$. The data were submitted to discriminant analysis and Student's $t$ test with equal variances, Mann-Whitney, F (ANOVA), Tukey and Kruskal Wallis, 5\% significance level. Results: Dominant nasal type in the Brazilian population was the mesorine. Males showed nasal height and width values greater than those of females, with statistically significant differences in all measurements ( $p \leq 0.021)$ and $\mathrm{PC}$ of $76.6 \%$. Similar nasal measurements were found regardless of age $(p>0.05)$, with $P C$ of $41.7 \%$. Ancestral analysis revealed that black individuals have greater nasal width (26.35) and nasal index (53.67) than white ones (24.60 and 49.25), while mixed-race individuals showed intermediate values (25.36 and 52.13) $(p<0.05)$. Nevertheless, these measurements presented an estimated PC of $54.3 \%$. Conclusion: The Nasal Index can be better used for sex determination than for estimation of age and ancestry in the Brazilian population, as the latter showed intermediate and low percentage of correctness, respectively.

Keywords: Nasal cavity. Forensic anthropology. Sex characteristics. Ethnic groups. Age groups. 


\section{Introduction}

Despite presenting the same bone components, male and female skeletons have significant morphological differences ${ }^{1-3}$. In $77 \%$ of the cases $^{4}$, this provides important features for estimation of sex, ancestry and age of an individual by using anthropological analysis of their skull. In this scenario, nasal parameters have been considered a useful tool for such differentiation ${ }^{5,6}$.

The nose is situated in the middle portion of the face and its presence is crucial for the design of a harmonious and functional face ${ }^{6-8}$. There are peculiar shapes and features based on geographic origin and due to natural selection consequent to human evolution. Narrow and long noses are predominantly found in individuals who are ancestrally linked to cold and dry climates, whereas noses with broader and flattened structure are common in humans from tropical environments ${ }^{6}$.

The Nasal Index (NI) is an anthropometric parameter of great use in Forensic Sciences, with significant value in the analysis and classification of fossil remains and estimation of ancestry and sex of individuals whose identity is unknown. Most certainly, it also serves as a parameter for understanding the course of the human evolution ${ }^{5,6,9}$. Taking the frontal plane as a reference, the $\mathrm{NI}$ is determined based on the ratio between the maximum nasal width and the maximum nasal height.

Morphological and metric variability among distinct populations confers an obstacle to identification by Forensic Anthropology ${ }^{10}$. Thus, this study aimed to determine the percentage of correctness (PC) of the Nasal Index (NI) for determination of sex, ancestry and estimation of age in a sample of Brazilian identified skeletons.

\section{MATERIAL AND METHODS}

This study is in accordance with the 466/12 Resolution of the National Health Council, Ministry of Health, Brazil, which regulates research involving human beings. The project was previously submitted to and approved by the Research Ethics Committee at the Center for Health Sciences, Federal University of Paraíba (CAAE protocol no. 45781415.0.1001.5188).

This cross-sectional study encompassed a universe of 192 skeletons. The sample was comprised of 173 skulls obtained from the Professor Eduardo Daruge Laboratory of Forensic Physical Anthropology at Piracicaba Dental School, University of Campinas (FOP/UNICAMP), São Paulo, Brazil. The osteologic Collection of FOP/UNICAMP consists in 320 identified skeletons from Cemetry Parque Nossa Senhora da Conceição (Amarais), Campinas-SP, exhumed in 2014 with at least 3 years after the death event. It is composed by 136 female and 184 bones males from Brazilian Southeast region, with an age range from 15 to 100 years-old. As regards to ante mortem data, sex, age, cause of death, and ancestry are available for analysis.

Damaged skulls unfit for analysis were excluded from the sample. Damaged skulls were considered as such if presenting malformed piriform apertures, severe anomalies, presence of apparent traumas, or serious bone pathologies compromising their integrity. Therefore, the final sample consisted of 173 dry skulls. 
To the present study, we performed an anthropometric analysis of nasal cavity and analyzed it according to sex. The considered measures were maximum nasal width (NW), nasal height ( $\mathrm{NH}=$ ANS-nasion), and nasal index (leptorin, mesorine, and platyrrhine).

To prevent possible measurement bias while using the digital caliper (Stainless-Hardened ${ }^{\circledR}-150$ mm, Mauá, São Paulo, Brazil), we approximated its tips after each measurement and zeroed the equipment so that to minimize variability of the data.

In order to train the examiner, a pilot study was carried out prior to data collection following the same criteria adopted for the full-length study. A total of 25 skulls were selected from the aforementioned collection and submitted to analysis. A seven-day interval was considered between the first and second assessments so that to compare the results and check for examiner agreement. The Kappa statistics test showed satisfactory results concerning the measurements $(\geq 0.92)$, which indicated proper training of the examiner in relation to the study criteria. As no adjustments were necessary based on this pilot study, all 25 skulls were also included in the final sample, totaling 173 skulls.

The Nasal Index was calculated by the formula $\mathrm{NI}$ = nasal width/ nasal height multiplied by $100^{9,11-13}$. The maximum nasal width was established based on craniometric points located at the most lateral portion of each nose wing by positioning the caliper beam perpendicular to the nasal septum. The nasal height was determined by positioning the fixed jaw of the caliper at the nasion point (anatomical accident at the meeting of the inter-nasal suture and the frontonasal suture) and the movable jaw at the nasospinal point (located at the center of the anterior nasal spine), with the caliper being parallel to the median sagittal axis.

Data were submitted to descriptive and inferential analysis by Student's $t$ test with equal variances, Mann-Whitney, $F$ (ANOVA) and Kruskal Wallis, with a $5 \%$ significance level ( $p \leq 0.05)$. All analyses were carried out using the Statistical Package for Social Sciences, version 23.0 (SPSS Inc., Chicago, IL, USA). Discriminant analysis was applied to determine the PC of the method for estimation of sex and ancestry. This type of analysis provides a pondering function according to the value of each metric and variable.

\section{RESULTS}

The study sample had a mean age of 56.46 ( \pm 20.11 ) years, and a median of 58.00 years-old. As for age range, 34 (19.6\%) were up to 39 years; 56 (32.4\%) were aged between 40 and 59 years; and 83 (48\%) were 60 years or older. No significant difference was observed between the age ranges for any of the measures analyzed (Table 1). Individuals from all age ranges showed predominantly the mesorine nasal pattern $(\mathrm{NI}=47.9-53)$.

To the age estimation (Table 2), the skull score should be compared to the range described by the two discriminant functions. Minor measurements tend to belong to younger skulls (up to 39 years) because the centroid of this range lies in the quadrant where both coordinates are negative. The centroids of the other age groups do not present a pattern with immediate identification, but we noticed that higher 
Table 1. Distribution of the sample by age range according to nasal height and width, and Nasal Index of skulls. Piracicaba, SP, Brazil, 2017.

\begin{tabular}{|c|c|c|c|c|}
\hline \multicolumn{4}{|c|}{ Age Range } & \multirow{2}{*}{ p-value } \\
\hline $\mathrm{n}=173$ & Up to 39 years & 40 to 59 years & 60 or older & \\
\hline & Mean \pm SD (Median) & Mean \pm SD (Median) & Mean \pm SD (Median) & \\
\hline & $(n=34)$ & $(n=56)$ & $(n=83)$ & \\
\hline Nasal Height & $49.80 \pm 4.44(50.16)$ & $49.55 \pm 4.09(48.93)$ & $49.77 \pm 3.96(49.20)$ & $\mathrm{p}^{(2)}=0.942$ \\
\hline Nasal Width & $24.64 \pm 2.86(24.94)$ & $25.29 \pm 2.22(25.10)$ & $25.16 \pm 2.36(25.02)$ & $\mathrm{p}^{(1)}=0.508$ \\
\hline Nasal Index (NI) & $49.75 \pm 6.54(49.86)$ & $51.35 \pm 5.88(51.35)$ & $50.83 \pm 5.76(50.19)$ & $\mathrm{p}^{(1)}=0.335$ \\
\hline
\end{tabular}

(1): $\mathrm{F}$ test (ANOVA).

Table 2. Canonical Discriminant Function Coefficients and Functions at Group Centroids by age range according to nasal height and width, and Nasal Index of skulls. Piracicaba, SP, Brazil, 2017.

\begin{tabular}{|c|c|c|c|c|}
\hline $\begin{array}{l}\text { Canonical Discriminant } \\
\text { Function Coefficients }^{(1)}\end{array}$ & Nasal Height & Nasal Width & Nasal Index & Constant \\
\hline Function 1 & .389 & .144 & -.218 & -4.963 \\
\hline Function 2 & -.115 & .381 & .088 & -10.365 \\
\hline $\begin{array}{l}\text { Functions at Group } \\
\text { Centroids }^{(2)}\end{array}$ & Up to 39 years & \multicolumn{2}{|c|}{40 to 59 years } & 60 or older \\
\hline Function 1 & -.410 & \multicolumn{2}{|c|}{.201} & -.090 \\
\hline Function 2 & -.140 & \multicolumn{2}{|c|}{-.040} & .074 \\
\hline
\end{tabular}

(1): Unstandardized coefficients.

(2): Unstandardized canonical discriminant functions evaluated at group means.

Table 3. Distribution of the sample by ancestry according to nasal height and width, and Nasal Index of skulls. Piracicaba, SP, Brazil, 2017.

\begin{tabular}{|c|c|c|c|c|}
\hline \multicolumn{4}{|c|}{ Ancestry } & \multirow{3}{*}{ p-value } \\
\hline \multirow{3}{*}{$n=173$} & White & Mixed race & Black & \\
\hline & Mean \pm SD (Median) & Mean \pm SD (Median) & Mean \pm SD (Median) & \\
\hline & $(n=96)$ & $(n=49)$ & $(n=28)$ & \\
\hline Nasal Height & $50.22 \pm 3.91(49.96)$ & $48.91 \pm 4.65(49.17)$ & $49.32 \pm 3.39(48.86$ & $\mathrm{p}^{(2)}=0.158$ \\
\hline Nasal Width & $24.60 \pm 2.43(24.29)^{(A)}$ & $25.36 \pm 2.33(25.47)^{(\mathrm{B})}$ & $26.35 \pm 2.06(26.57)^{(\mathrm{B})}$ & $\mathrm{p}^{(1)}<0.001^{*}$ \\
\hline Nasal Index (NI) & $49.25 \pm 5.95(48.46)^{(A)}$ & $52.13 \pm 5.20(51.72)^{(8)}$ & $53.67 \pm 5.72(52.23)^{(B}$ & $\mathrm{p}^{(1)}<0.001^{*}$ \\
\hline
\end{tabular}

values tend to be classified in the intermediate range (40 to 59 years), because the centroid has a higher value, while intermediate values tend to be classified in the age group over 60 or older.

In order to determine ancestry, the sample was divided into three groups, as follows: white $(n=96,55.5 \%)$, mixed-race $(n=49,28.3 \%)$ and black $(n=228,16.2 \%)$. Significant differences were observed between the ancestral categories and nasal width and $\mathrm{NI}-$ but not between ancestry and nasal height. As seen in Table 3, the means were corre- 
Table 4. Canonical Discriminant Function Coefficients and Functions at Group Centroids by ancestry according to nasal height and width, and Nasal Index of skulls. Piracicaba, SP, Brazil, 2017.

\begin{tabular}{lcccc}
\hline $\begin{array}{l}\text { Canonical Discriminant } \\
\text { Function Coefficients }\end{array}$ & Nasal Height & Nasal Width & Nasal Index & Constant \\
\hline Function 1 & .310 & -.271 & -.086 & 1.356 \\
\hline Function 2 & .152 & .305 & .027 & -13.730 \\
\hline $\begin{array}{l}\text { Functions at Group } \\
\text { Centroids }\end{array}$ & White & Mixed race & Black \\
\hline Function 1 & .411 & -.401 & -.708 \\
\hline Function 2 & .019 & -.137 & .173 \\
\hline
\end{tabular}

(1): Unstandardized coefficients.

(2): Unstandardized canonical discriminant functions evaluated at group means.

Table 5. Distribution of the sample according to Nasal Index, nasal height, and nasal width. Piracicaba, SP, Brazil, 2017.

\begin{tabular}{lcccc}
\hline \multirow{2}{*}{ Variables $(\mathrm{n}=173)$} & \multicolumn{4}{c}{ Statistics } \\
\cline { 2 - 5 } & Mean $\pm \mathbf{s d}$ & Median & Minimum & Maximum \\
\hline Nasal Index & $81,00 \pm 11,95$ & 79,15 & 56,21 & 127,01 \\
\hline Nasal height & $49.72 \pm 4.01$ & 49.72 & 37.86 & 60.50 \\
\hline Nasal width & $25,10 \pm 2,42$ & 25,02 & 19,59 & 35,07 \\
\hline
\end{tabular}

spondingly lower among white individuals. The ancestral types white and mixed-race showed a predominance of the mesorine nasal pattern $(\mathrm{NI}=47.9-53)$, whereas black individuals were characterized by the platyrrhine nasal pattern.

Table 4 presents values to the discriminant function and the centroids of each ancestral group. It is observed that the two discriminant functions present higher values for nasal height (0.310) and for nasal width (0.305) in functions 1 and 2, respectively. In particular in Function 1, the weight for the nasal height is also high, but with a negative sign and, as the constant is lower, it is expected that high values for nasal height and low for nasal width, favor classification as white. On the contrary, it is expected that high values for nasal width and low for nasal height favor classification as black. Moderate values for both favor classification as mixed race. It is worth remembering that the nasal index has little influence on the classification of ancestry since its values are low for both functions.

Of the 173 skulls under analysis, 93 (53.8\%) were males. The mean, sd, minimum, and maximum values of Nasal Index, Nasal height, and Nasal width for the total group are described in Table 5. As shown in Table 6, the measurements obtained for males had greater values than those from females for all variables, with statistically significant differences $(p<0.05)$.

Using the discriminant function analysis (canonical median values) and multiplying each value of the function by the value measured in the skull, if the sum of the products is greater than zero we classify the individual as male. In addition, the centroids 
Table 6. Distribution of the sample by sex according to nasal height and width, and Nasal Index of skulls. Piracicaba, SP, Brazil, 2017.

\begin{tabular}{lccc}
\hline \multicolumn{3}{c}{ Sex } & \\
\cline { 1 - 2 } $\mathrm{n}=173$ & Male & Female & p-value \\
\cline { 2 - 3 } & Mean \pm SD (Median) & Mean \pm SD (Median) & \\
\cline { 2 - 3 } Nasal Height & $(\mathrm{n}=93)$ & $(\mathrm{n}=80)$ & \\
\hline Nasal Width & $51.66 \pm 3.51(51.96)$ & $47.43 \pm 3.47(47.31)$ & $\mathrm{p}^{(1)}<0.001^{*}$ \\
\hline Nasal Index $(\mathrm{NI})$ & $25.50 \pm 2.46(25.47)$ & $24.64 \pm 2.31(24.54)$ & $\mathrm{p}^{(2)}=0.021^{*}$ \\
\hline
\end{tabular}

$(\star):$ Significant difference at $5.0 \%$.

(1): Student's $t$ test with equal variances.

(2): Mann-Whitney test.

Table 7. Canonical Discriminant Function Coefficients and Functions at Group Centroids by sex according to nasal height and width, and Nasal Index of skulls. Piracicaba, SP, Brazil, 2017.

\begin{tabular}{lcccc}
\hline $\begin{array}{l}\text { Canonical Discriminant Function } \\
\text { Coefficients }\end{array}$ & Nasal Height & Nasal Width & Nasal Index & Constant \\
\hline Function 1 & .157 & .110 & .165 & -15.870 \\
\hline Functions at Group Centroids ${ }^{(2)}$ & & Male & \multicolumn{2}{c}{ Female } \\
\hline Function 1 & & .606 & -.719 \\
\hline
\end{tabular}

(1): Unstandardized coefficients.

(2): Unstandardized canonical discriminant functions evaluated at group means.

Table 8. Percentage of correctness of the measures nasal height and width, and Nasal Index combination for sex estimation in skulls. Piracicaba, SP, Brazil, 2017.

\begin{tabular}{lccc}
\hline & \multicolumn{2}{c}{ Predicted Group Membership } & \multicolumn{2}{c}{ Total } \\
\cline { 2 - 4 } Sex & Male & Female & N $\%$ \\
\hline Male & N $\%$ & $19(22.1)$ & $93(100.0)$ \\
\hline Female & $74(77.9)$ & $60(75.0)$ & $80(100.0)$ \\
\hline 76.6\% of original grouped cases correctly classified. & & \\
\hline
\end{tabular}

of each group indicate that higher measures suggest the classification of the skull as male (Table 7).

Table 8 shows the PC of each measure for estimation of sex. We can see that the method was able to correctly estimate sex in 74 (77.9\%) out of the 93 male skulls. As for female skulls, the method correctly determined sex in 60 (75.0\%) skulls and failed to do so in $19(22.1 \%)$ pieces out of the 80 previously cataloged skulls. Hence, this method can properly estimate sex with a PC of $76.6 \%$.

The area under the ROC curve is a measure of the performance of a test (test accuracy index). The hypothesis is considered null when there is an area under the curve of 0.50 , and satisfactory performance when above 0.70 . In this study, we found that the test was satisfactory in terms of sex (0.776) (Figure 1), moderate for ancestry classification (0.632) and poor for age estimation (0.516). 


\section{ROC Curve}

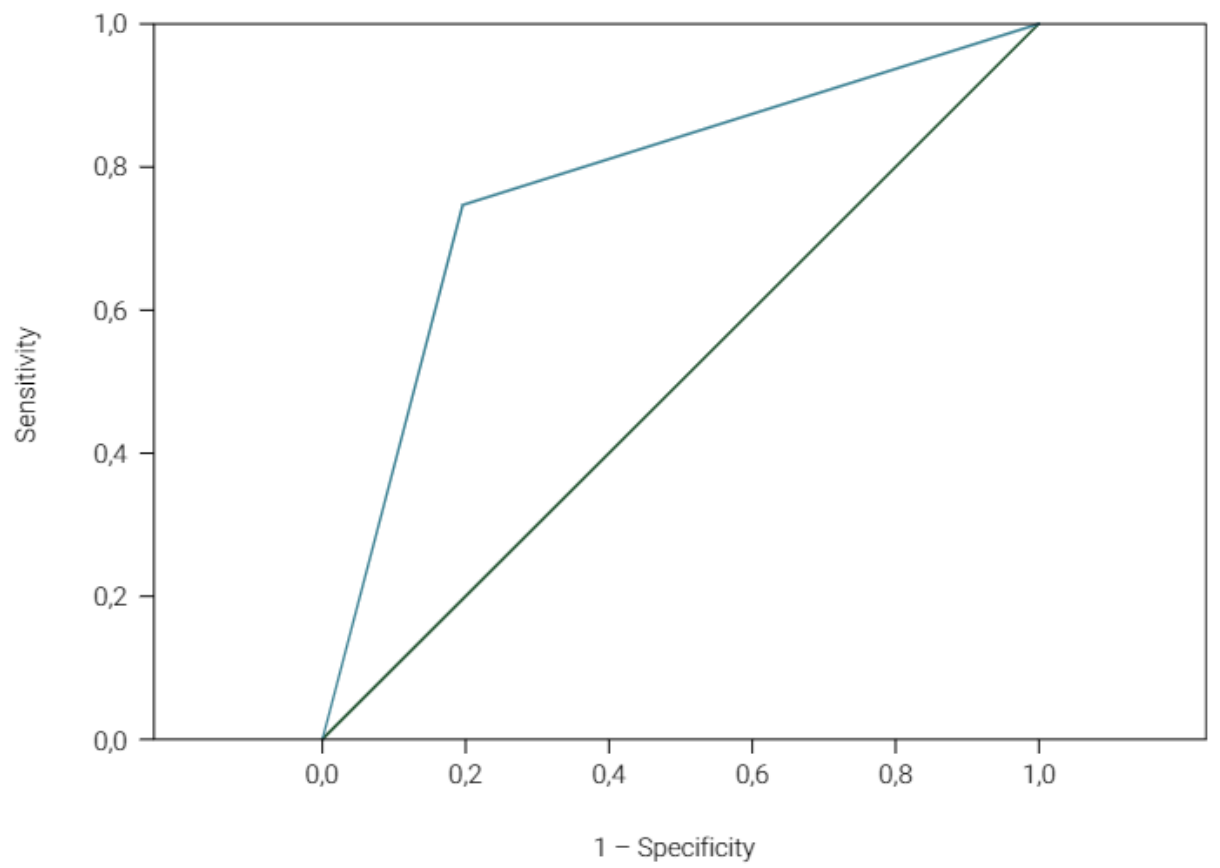

Figure 1. Area under the ROC curve showing the accuracy of nasal measures according to sex. Piracicaba, SP, Brazil, 2017.

\section{DISCUSSION}

Since the 19th century, there has been a considerable interest in classifying human based on anthropometry and morphology of nasal parameters, such as the Nasal Index ${ }^{14}$. Studies have shown that nasal size, angles, shapes and types vary in relation to sex, age, and ancestry ${ }^{14,15}$. This scenario has encouraged the establishment of specific patterns for each population, particularly in Brazil, where colonization by several peoples has shaped a very diverse phenotypic background.

Brazil is a country with continental dimensions, which is composed of populations of African, European and American Indigenous origin. The proportion of the contribution of each single component varies according to the territorial region in such a way that phenotypic discrepancies are not always apparent. This is so true that even the whitest of the Brazilians can harbor genetic traces of the black ancestry and vice-versa ${ }^{16,17}$, thereby making it possible to think of a "Brazilian ancestry".

The Sao Paulo state in Brazil, from where the study samples were collected, has been a destination of migrants from across the country over the past decades. As a result, there has been an accentuated diversification concerning the origin of the Brazilian population, which also includes components of Japanese origin ${ }^{18}$. Thus, the classical division into three ancestral groups (white, mixed-race and black) is practical for population-based surveys but seems to be rather simple for other purposes, given the expressive miscegenation ${ }^{19}$.

Quantitative and qualitative variations should be considered during the identification process $^{18}$ so that to determine parameters for differentiation of sex and age. The 
association of methods is fundamental to provide credibility to forensic findings ${ }^{20}$, and metric analyses of the nose constitute important tools for the forensic sciences.

With regard to sex, males were found to have mean values 2 to $4 \%$ greater than those of females ${ }^{19}$. These findings are in line with our study, which showed that the measurements were greater in males than in females for the metric variables of interest, and also agree with several studies carried out with other populations ${ }^{6,21-24}$. Hegazy ${ }^{24}$ investigated an Egyptian sample of 290 subjects, 144 males and 146 females, aged 1 month to 65 years. The author observed significant differences in nasal width between sexes from the $12^{\text {th }}$ year of life and particularly in individuals aged over 20 years. The author also pointed out that nasal height was greater in males from the age of 12 , with no statistical significance though. There was a significant difference in the Nasal Index between males and females from the second decade of life. Males were found to have the mesorine nasal type while females the leptorin one (thinner). This is in disagreement with the findings reported herein, in which both sexes showed a predominance of the mesorine nasal pattern.

Bustamante et al. ${ }^{23}$ investigated the nasal height, width and the NI of a Chilean sample. The authors found results similar to those reported herein: mean nasal height higher in males, with lower $\mathrm{NI}$ than that of females. These findings reveal a tendency of men and women to present the leptorin (46.58) and mesorine (49.46) biotypes, respectively. Contrarily, the authors found that the mean nasal width of females was greater than that of males.

Nasal structures continue to develop throughout the course of life, in such a way that aged people tend to have wider noses than young ones ${ }^{25}$. One hypothesis for this phenomenon lies in the close correlation between nasal dimensions, including the Nasal Index, and oxygen consumption ${ }^{26}$. The process of natural selection has modified the size and shape of nasal structures so that to manage the amount of air to be processed. Thus, men who theoretically need to consume more oxygen during demanding physical activities would need wider noses to do so than women from the same population ${ }^{14,24}$.

The use of the Percentage of Correctness are meaningful to evaluate to what degree data measure what they should measure, or how much the results of a measurement correspond to the true state of the phenomenon measured ${ }^{27}$. In our study, we used discriminant analysis to trace this phenomenon. The PC for sex determination was found to be $76.6 \%$. This percent indicates that such measurements are good for aiding the estimation of sex in this Brazilian sample. However, to undoubtedly say if this parameter can be used for sex estimation in all Brazilian population, studies with different methodological approaches must be performed in order to obtain more information on this hypothesis.

We found that the $\mathrm{NI}$ showed little importance in determining the ancestry of the Brazilian population. This fact could be explained by the great miscegenation that occurred in Brazil among whites, blacks and indigenous. As for age estimation, the study sample had already completed bone growth, which occurs in women up to 22 years and in men up to 25 years ${ }^{5}$. 
The morphological and metric variability among distinct populations makes it difficult for Forensic Anthropology to complete the identification process. Hence, further population-based studies are needed along with the establishment of mathematical formulae for each group ${ }^{10}$. The tables and regression formulae of European and American origin should not be used by Brazilian Forensic Anthropologists, once Brazilians bear unique features due to ethnic miscegenation and nutrition. Therefore, specific techniques should be available to determine the anthropometric parameters of Brazilian corpses ${ }^{28}$.

Forensic techniques provide a range of possibilities to determine human identity, many of which presenting solid scientific background. It is up to experts to make use of the best method available for each case, taking into account the peculiarities and conditions of the samples. An individual identification method does not overlap another and, depending on each case, the indication and application of a given method instead of another makes it more efficacious to complete the identification process. Thus, the more scientific and reliable techniques are used for identification, the more robust the process.

The present study showed that the mesorine nasal type predominates among the Brazilian population sample analyzed. Statistically significant differences were observed between nasal dimensions (height, width and Nasal Index) and sex, with greater dimensions in males and high PC between males and females. Nevertheless, the NI showed low PC for age estimation. Thus, it may be concluded that the Nasal Index can be used for sex differentiation of bone remains.

\section{ACKNOWLEDGEMENTS}

The authors would like to thank the Coordination for the Improvement of Higher Education Personnel (CAPES) and the Pernambuco Research and Technology Foundation (FACEPE) for financial support.

\section{REFERENCES}

1. Kim YK, Lee E, Oh JW, Han SY. Sexual dimorphism of craniomandibular size in the eurasian otter, Lutra lutra, from South Korea. J Vet Med Sci. 2018 Apr 18;80(4):594-600. doi: 10.1292/jvms.17-0441.

2. Manjunath TH, Raghavendra R, Umesh SR. Study of Identification of Sex of Adult Human Skull by Cranial Circumference. Indian J Forensic Med Toxicol. 2017 Jan;11(1):92-5.

3. Lima LNC, Oliveira OF, Sassi C, Picapedra A, Francesquini Júnior L, Daruge Júnior E. Sex determination by linear measurements of palatal bones and skull base. J Forensic Odontostomatol. 2012 Jul; 30(1):38-44.

4. Caldas IM, Magalhães T, Afonso A. Establishing identity using cheiloscopy and palatoscopy. Forensic Sci Int. 2007 Jan;165(1):1-9. doi: 10.1016/j.forsciint.2006.04.010.

5. França GV. [Legal medicine]. Rio de Janeiro: Guanabara Koogan; 2017. Portuguese.

6. Jimoh RO, Alabi SB, Kayode AS, Salihu AM, Ogidi OD. Rhinometry: spectrum of nasal profile among Nigerian Africans. Braz J Otorhinolaryngol. 2011 Sep-Oct;77(5):589-93.

7. Daruge E, Daruge Júnior E, Francesquini Júnior L. [Treaty of Legal Dentistry and Deontology]. São Paulo: Santos; 2017. Portuguese. 
8. Barros IR. [The importance of rugoscopy palatine analysis in Forensic Dentistry]. Acta Ciênc Saúde. 2016;5(2):144-56. doi: 10.4103/0975-1475.119775. Portuguese.

9. Anwar A, Sardar KP, Nasir S, Waqar SM. Knowledge, Attitude and Practice of Forensic Odontology among Graduates and Post Graduate Students at Dow University of Health Sciences (DUHS). J Pakistan Dent Assoc. 2016 Sep;25(3):110-4.

10. Veyre-goulet SA, Mercier C, Robin O, Guerin C. Recent human sexual dimorphism study using cephalometric plots on lateral teleradiography and discriminant function analysis. J Forensic Sci. 2008 Jul;53(4):786-9. doi: 10.1111/j.1556-4029.2008.00759.x

11. Li C, Jiang J, Kim K, Otto BA, Farag AA, Cowart BJ, et al. Nasal Structural and Aerodynamic Features that may Benefit Normal Olfactory Sensitivity. Chem Senses. 2018 Apr 23;43(4):229-237. doi: 10.1093/chemse/bjy013.

12. Silva AMBR, Magri LV, Andrade LM, Silva MAMR. Three-dimensional analysis of facial morphology in Brazilian population with Caucasian, Asian, and Black ethnicity. J Oral Res Rev. 2017 Mar;9(1):1-7. doi: 10.4103/2249-4987.201405.

13. Liebenberg L, Stull KE, L'Abbé EN, Botha D. Evaluation of cranial indices among south Africans. J Forensic Sci. 2015 Sep;60(5):1277-82. doi: 10.1111/1556-4029.12770.

14. Leong SC, Eccles R. A systematic review of the nasal index and the significance of the shape and size of the nose in rhinology. Clinic Otolaryngol. 2009 Jun;34(3):191-8. doi: 10.1111/j.1749-4486.2009.01905.x.

15. Uzun A, Ozdemir F. [Morphometric analysis of nasal shapes and angles in young adults]. Braz J Otorhinolaryngol. 2014 Sep-Oct;80(5):397-402. doi: 10.1016/j.bjorl.2014.07.010.

16. Kehdya FS, Gouveia MH, Machado M, MAgalhães WC, Horimoto AR, Horta BL, et al. Origin and dynamics of admixture in Brazilians and its effect on the pattern of deleterious mutations. Proc Natl Acad Sci U S A. 2015 Jul 14;112(28):8696-701. doi: 10.1073/pnas.1504447112.

17. Durso DF, Bydlowski SP, Hutz MH, Suarez-Kurtz G, Magalhães TR, Pena SDJ. Association of genetic variants with self-assessed color categories in Brazilians. PLoS One. 2014 Jan 8;9(1):e83926. doi: $10.1371 /$ journal.pone.0083926.

18. Ayoub F, Jassar H, El Husseini H, Aoun N, Sayah F, Salameh Z. Correlation of oral, genetic, and radiological parameters involved in human identification in forensic dentistry. J Int Oral Health. 2016 Apr;8(6):725-8. doi: 10.2047/jioh-08-06-16.

19. Toledo Avelar LE, Cardoso MA, Santos Bordoni L, de Miranda Avelar L, de Miranda Avelar JV. Aging and Sexual Differences of the Human Skull. Plast Reconstr Surg Glob Open. 2017 Apr;5(4):e1297. doi: $10.1097 /$ GOX.0000000000001297.

20. Furlan ACK, Nogueira BS, Demetrio ATW, Lolli LF. [Carrea's method validation in northwest of Paraná State Brazil]. Rev Bras Odontol Legal. 2016 Mar;3(1):15-23. Portuguese.

21. Steyn M, Işcan MY. Sexual dimorphism in the crania and mandibles of South African whites. Forensic Sci Int. 1998 Nov;98(1-2):9-16.

22. Oladipo GS, Olabiyi AO, Oremosu AA, Noronha CC. Nasal indices among major ethnic groups in southern Nigeria. Scient Res Essay. 2007 Jan;2(1):020-2.

23. Bustamante MF, Fuentes R, Flores T, Sanhueza A. [Relation between Superior Facial Index and Nasal Index in Chilean Adult Crania]. Int J Morphol. 2011;29(3):810-5. Spanish.

24. Hegazy AA. Anthropometric study of Nasal Index of egyptians. Int J Anat Res. 2014;2(4):761-7. doi: 10.16965/ijar.2014.544

25. Zankl A, Eberle L, Molinari L, Schinzel A. Growth charts for nose length, nasal protrusion, and philtrum length from birth to 97 years. Am J Med Genet. 2002 Sep;111(4):388-91. doi: 10.1002/ajmg.10472. 
26. Hall RL. Energetics of nose and mouth breathing, body size, body composition, and nose volume in young adult males and females. Am J Hum Biol. 2005 May-Jun;17(3):321-30. doi: 10.1002/ajhb.20122.

27. Silveira DP, Artmann E. Accuracy of probabilistic record linkage applied to health databases: systematic review. Rev Saude Publica. 2009 Oct;43(5):875-2.

28. Mellega R. (Validation of the main techniques of determination of the existing stature and applied in samples of Brazilian cadavers] [dissertation]. Piracicaba: Piracicaba Dental School of the University of Campinas; 2004. Portuguese. 